\title{
CORRIGENDUM
}

\section{Diversity and abundance of diazotrophic microorganisms in the South China Sea during intermonsoon}

Pia H Moisander, Roxanne A Beinart, Maren Voss and Jonathan P Zehr

The ISME Journal (2008) 2, 996; doi:10.1038/ismej.2008.84

Correction to: The ISME Journal (2008) 2, 954-967; doi:10.1038/ismej.2008.51

The authors of the above noted an error in the footnote to Table 1 . The footnote should read: The three different cyanobacterial symbionts in diatoms are Het-1, Richelia (in Rhizosolenia), Het-2, Richelia (in Hemiaulus) and Het-3, Calothrix (in Chaetoceros). 